\title{
'I just do as expected.' Teachers' implementation of Continuous Assessment and challenges to curriculum literacy
}

Rejoice N. Nsibande $a^{*}$ and Maropeng M. Modiba b

a Department of Education Innovation, University of Pretoria, Pretoria, South Africa; bDepartment of Education Studies, University of Johannesburg, Johannesburg, South Africa

\begin{abstract}
The paper reports on a study that clarifies the nature and scope of the challenges experienced by primary school teachers in Swaziland when using Continuous Assessment (CA) as a tool to improve teaching and learning. Through the use of classroom observations and stimulated recall interviews, we sought to understand the significance of the choices they made to meet the requirements of the prescribed lesson objectives. Their accounts for the assessment exercises they used reflect their understanding of the content they had to teach, the discipline from which it was drawn and intentions of CA programme. In conclusion, we provide cues that may be useful to further these teachers' curriculum literacy.

Keywords: curriculum literacy; Continuous Assessment; social studies education;

Swaziland
\end{abstract}

\section{Introduction}

Continuous Assessment (CA) has been introduced in Swaziland to promote equal opportunity for academic success for every individual primary school child. Learners' achievements are to be measured not only on the basis of their ability to remember content, but also against clear criteria and standards that define cognitive development. Its aims can be summarised as follows: to improve teaching and learning by integrating it with assessment; to encourage primary school learners to develop life skills that could help them in case they drop out of school; and to provide policy makers with information useful for improving the quality of education in 
Swaziland (Ministry of Education CA Handbook, 1994). In short, there are three goals of CA: influence teaching, promote meaningful learning and improve test scores.

CA requires teachers who are able to reflect on learners' work in a manner that encourages creativity in teaching. Tomaney $(1994,171)$ describes them as manually gifted, theoretically talented and able to diagnose and act effectively when responding to the needs of the daily life of their classrooms and schools. These are teachers whose decision making is not driven by technical rationality, but whose thinking and teaching is focussed on the needs of learners. They demonstrate agency that CochranSmith and Lytle (1999, 279) describe as "a deep and passionately enacted responsibility to students' learning and life chances, and to transforming the policies and structures that limit students' access to these opportunities." Stenhouse's (1975, 91) view is that this is a role in which a teacher needs to have "skills in finding things out ... But more than that...a continual refinement of a philosophical understanding of the subject he is teaching and learning, of its deep structures and their rationale."

The paper reports on a study we conducted to explore the presence of these qualities among primary school teachers in Swaziland. As researchers in teacher development and curriculum, we were interested in finding out how they translated the principles of CA in practice. We were not involved in the conceptualisation and implementation of this programme. It was a government initiative.

We studied a case of Swazi primary school teachers who had received professional inservice support to enable them to use assessment to improve teaching and learning in 
their classrooms. Their choice of assessment tasks was considered as reflecting the professional competence they had acquired because of the introduction of the CA programme (Schneider and Ingram 1990). According to Schneider and Ingram it is only when people know about policy and its expectations and are provided with appropriate resources, that they develop the capacity to implement it. In their view "capacity programs assume that the target groups will have sufficient incentive or motivation to participate in the activity, or change their behaviour, if they are properly informed and have the necessary resources" (Schneider and Ingram 1990, 518). Therefore, the inquiry model we used was informed by three principles, namely: (a) CA could not have been imposed on teachers without taking it for granted that they had the capacity to use assessment as a resource to improve teaching and learning, (b) without the required capacity, teachers would ignore or deviate from the ideals of CA, (c) teachers' understanding of CA could not be developed without creating an environment in which the articulation of its theory would make sense.

In Gramsci”s $(1971,78)$ view “... the task necessary to bring forth change ... would be to base one's strategy on the commonsense of the people, from that folklore shape it to a more refined, or thought-through and in a sense principled world view." Challenging common sense should bring about cultural formation and also help to develop critical thinking that is essential to a particular ideology. For this to happen it is important to take personal experiences as a starting point. In Gramsci's view, people generally have a certain intellectual and cultural level that needs critical preparation for them to be able to adopt the characteristics of the ideology to which they are being exposed. He sees such adoption as bringing about an "intellectual revolution", and further asserts that "it is not just the ideas that require to be 
confronted but the social forces behind them and, more directly, the ideology these forces have generated" (Gramsci 1971, 321). In short, it is important to create ideological hegemony; if there is to be consistency between the way people think and the way they are to act in particular situations. Such a process would ensure that they are exposed to principles that would guide their actions in accordance with what the ideology expects them to do. As good sense such principles should influence decisions on actions that would be deemed appropriate for particular cultural or ideological circumstances. Developing this sense or intellectual growth in people is a process that involves internalising ways of thinking, acting and imagining within an ideology. The adoption of this required ideology would thus imply in practice, the development of a particular consciousness.

Cardona (2000) and Martinez et al. (2000) also assert that unless teachers get exposed to better methodologies and adequate opportunities to change their taken for granted beliefs and attitudes, it cannot be assumed that they would be in a position to engage in new responsibilities and consequently change their practices. The way they worked before needs to be challenged to make them rethink the nature of their work.

In their view such change requires a change in consciousness. Therefore, in the case of this study, unless teachers' prior beliefs, acquired through a PTC or PTD, in relation to their work were challenged, and attempts made to raise a new consciousness, they were bound to continue in the roles they learnt from these programmes. This would be a consciousness that would make them realize that it is important to learn the general logical character of the respective disciplinary knowledge they have to teach and to conduct a close examination of the subject 
matter with respect to patterns of meaning characteristic of the discipline to which it belongs before teaching it. It is in this sense that assessment should be seen as primarily concerned with an ability of the teacher to foresee and control the activities and interpret work that is appropriate to the teaching-learning experience that is desired. In short, it places great importance on in general, the art of lesson preparation and, specifically, the design of assessment items that are addressing the desired outcomes of lessons. As a teaching and learning improvement strategy, it requires on the part of teachers knowledge to speak about a discipline and to reflect on the quality of its knowledge and processes that are likely to lead to the acquisition of this knowledge and constitute working in the discipline.

\section{Research Design}

We employed what Merriam (2002) refers to as 'basic interpretive qualitative' research design to capture the reasons the teachers gave for the assessment items and tasks they chose to use in their lessons. Their accounts reflected how they used learners' performance in the assessment tasks for them to reinforce or remedy teaching and learning. These accounts are theorised on the basis of Merriam's (1998, 2002) 'inductive research strategy’.

The inquiry model helped us to clarify how the teachers diagnosed and dealt with (Tomaney 1994) the learners' learning needs in their classrooms. We considered their practices as having three important principles, namely (a) they were context-bound in relation to their history, experiences, skills and resources; (b) they resulted from the teachers' motivation to improve the quality of primary school education in Swaziland and, (c) they were a demonstration of the teachers' capacity to implement CA and 
provide meaningful education by engaging with the learners' responses. The teachers' explanations of how they implemented CA needed to reveal how understandings of this assessment programme facilitated access to the concepts and principles they had to teach and the objectives set for doing so. These accounts were to reveal their curriculum expertise. In short, the authors assumed an inextricable link between the teachers' accounts and their understanding of what was required if CA was to be used effectively to improve teaching and, subsequently enable the learners' to meet the requirements of the syllabus aims. As Day (1999) also asserts:

Just as classrooms must be learning environments in which learners receive, respond to and actively participate in generating knowledge, so professional development opportunities must provide a range of learning experiences which encourage teachers to reflect upon and inquire into their thinking and practice...(Day 1999, 201)

Since the study was not aimed at making generalisations, but rather at identifying ways in which teachers used how the learners tackled the assessment tasks as resource to reinforce or remedy learning, we needed first, to look at these tasks to establish whether or not they addressed the aims of the syllabus and, second, how teachers viewed them. Because of the limited scope of this paper, out of the eight teachers we use data obtained from four of them to illustrate how their taken-for-granted and contextually bound dispositions diminished the possibility of improving teaching and learning. Not only their assessment practices but also their views on them demonstrated this.

The teachers were oriented to the purpose of the study through a meeting in which they were broadly informed of its purpose and what was expected from them in terms of shedding light on how they used learners' performance to rethink their teaching. We were interested in how their strategies addressed principles advocated primarily 
by Tomaney (1994) as important when 'using CA specifically, as a professional development strategy. Semi- structured interviews (Moser and Kalton 1986) were used to encourage teachers to reflect on the assessment tasks, noting in particular, how they revealed the strengths and shortcomings in learning and indirectly their teaching.

Data collection was thus motivated by an interest to understand, firstly, how teachers understood the relevance of the performance of learners to their teaching. Secondly, how they viewed the assessment tasks and items they used as diagnostic tools for the learners strengths and weaknesses. Thirdly, how they used the evidence in devising teaching strategies responsive to them.

The interviews were interactive, conversational and moved between the teachers commenting on how they decoded and encoded the aim of the syllabus into lessons and seeking clarity on what they thought made the provided assessment tasks useful to improve teaching and learning. The interview data was tape-recorded.

In trying to encourage the teachers to account for their assessment strategies, emphasis was on enhancing an appreciation of the relationship between their choice of assessment items and structure of these tasks to the aims of the syllabus. Drawing on Tomaney's description of teachers who are competent to deliver CA when responding to the needs of the daily life of their classrooms and schools, helped us to focus quite explicitly on these qualities. We specifically looked for how the assessment procedures were focussed on the needs of learners and demonstrated the agency that Cochran-Smith and Lytle and Stenhouse appeal for in their writings 
referred to earlier herein.

\section{Sampling}

The process targeted Grade Six teachers who had participated in workshops that provided professional support for the implementation of $\mathrm{CA}$ following a series of other workshops. The workshops were concurrently run in the four regions of Swaziland, namely, in Hhohho, Manzini, Shiselweni and Lubombo. In each region schools were divided into two zones and a week was allocated to each zone. This meant that workshop presenters were teaching the same material for two weeks, but to two different groups of teachers. Researchers participated as observers in a workshop arranged for the Manzini region at Mjingo High School (venue for workshop). The 23 schools that participated in the Salesian - Ekutsimuleni zone were all in the rural or semi-urban areas and made a naturally bounded group (LeCompte and Preissle 1993). In the case of this study, features that binded the teachers had to do with the availability of resources and the profile of schools.

The selection of the sample was also restricted to one area of learning in which we had expertise. Guidance in this regard came from the works of (Flick 1998, Merriam 1998), who point out that a researcher could decide on a small sample size if the aim is to do an analysis that is in depth. Important to also note is that, this study was not meant to generalise or be representative but to help us understand curriculum issues that underpinned the way teachers' worked with assessment. We then decided, as specialists in History, to work with Grade Six Social Studies teachers. Also, professional development programmes for CA focussed mainly on improving teachers who taught this class. As data sources these teachers were few but constituted a 
convenient, purposeful and information rich sample (cf Merriam 1998; Gall et al. 1999). Even though 11 teachers satisfied the criteria to participate in the study, only 8 agreed to be part of the study.

The participants had either a Primary Teacher's Certificate (PTC) or a Primary Teacher's Diploma (PTD). Even though there are still a number of teachers with PTC, in 1987 this programme was phased out and replaced with the PTD as the basic teacher education programme for teachers at primary school level. The PTD is a three year post O-level qualification. Students specialise in one of the following combinations: Mathematics and Science, English and siSwati, Agriculture and Home Economics, History, Religious Knowledge and Geography (Social Studies) (NERCOM 1985, 88).

\section{Research Tools}

Classroom observations and unstructured interviews were used.

Observations were used to document assessment practices in relation to lesson objectives including how the learners tackled the tasks given during the lessons. The lessons were video-recorded. Social Studies was taught twice a week.

Over a period of three months, all the schools were visited three times. For each teacher the last two 45-minute lessons were recorded. The first visit was to introduce both the teachers and their learners to our presence in their classrooms. Hand-written notes were made during these visits. The next visits were for video-recording lessons and the last for reviewing the recorded material. The first recordings were meant to 
lessen the effects such a devise was likely to have on teachers. Lessons recorded in the second visits were used to anchor the interviews that provided an opportunity for teachers to account for their assessment practices (Bilmes 1986).

After conducting the initial classroom observations, to avoid cases where teachers' practices were influenced by the concerns of the researcher, nothing was discussed with them until all observations were done

Interviews on the third lessons were to elicit teacher's views on the value of using CA to their teaching. These insights and accounts were recorded in the teachers' original language, namely, isiSwati. Each interview was adjusted to the particular issues that were singled out by the teachers and were considered relevant to the goals of CA. An audio tape recorder was used to ensure that the process moved quickly and responses could later be translated and transcribed verbatim.

\section{Research Process}

The research had three strands: First, we looked at the official curriculum guidance documents used by the teachers. They included Social Studies teachers' guide and a textbook for the learners. Designers of these materials indicated that these should be used as guides and not to be followed slavishly. Then we conducted classroom observations to see how teachers were dealing with the assessment tasks that were suggested for use for different lessons. Of particular interest to us was how the professional autonomy afforded to them by CA was taken advantage of when making decisions about the suitability of these tasks. Finally, unstructured interviews were 
conducted to encourage them to account for their choice of these tasks and how they mediated them to learners.

Teachers were asked to watch their lessons on video and account for, in particular, their choice of assessment items and classroom interaction with learners in the last phases of the lessons, that is, at the time they were giving class-work as assessment. Uninterrupted and depending on their preference, either they reviewed the whole lesson and then talked about it or talked about it in the process of reviewing. The latter meant stopping and replaying the video whilst reviewing. Engaging their minds (Davies et al 2000) in this way produced data that illuminated what were influential factors that guided their practices.

The interviews became not only a means to clarify data but they also provided an opportunity for dialogue between the teachers and the researchers (Lather 1986, Gitlin 1990), that encouraged them to think about what they had taken for granted when choosing to use the suggested assessment exercises and activities. In a way, the process raised their awareness and appreciation of what was important to do for CA to be conducted successfully.

Thinking beyond the guidance they received on the CA programme was not going to come naturally to the teachers, but required that their consciousness be raised. It could no longer be assumed that they would be able to pick up on their own what was essential to the language of CA. It was only when helped to understand why they had to use alternative strategies to the ones to which they were accustomed that they could change their assessment practices. Therefore, as part of the research process we urged 
them to reflect more deeply on their current practices and the justifications they had for them.

There was a need for an approach that would provide them with a chance to realise how they could change their assessment strategies. Further interaction with them was thus informed by the concerns of educative research. We had to consider seriously the advice of Gitlin and Russell (1988, 243), when they quote Habermas that "it is impossible for the researcher to understand the 'subject' unless he/she enters into dialogue with the subject aimed at mutual understanding Therefore, the intent of the dialogical method employed here was not simply to indicate strengths and shortcomings in the way teachers worked with curriculum objectives and the suggested assessment tasks. Rather, it was meant to identify and examine the circumstances that contributed to these shortcomings and how they were embedded in their particular historical context. Of importance was that teachers should realize assumptions that shaped their choice of and the nature of assessment tasks they gave to learners.

Our interaction with them was thus not judgemental but aimed at transforming their understanding of CA, creating a situation where they could view their assessment practices in a different way and further rethink how they could re-inforce or serve the aims of the programme. Through dialogue we examined their taken-for-granted dispositions and the extent to which they facilitated, or not, the fulfilment of the requirements of CA. In this specific situation, an understanding of $\mathrm{CA}$ as an aspect of the curriculum design process was crucial. 
According to Rescher (1988), it is important for people to understand a plan of action in order to develop commitment. When people understand the significance of a particular action they gain interest in it as they learn how it can benefit them. When the reasons for actions are properly explained to people, it is easy for them to be motivated as they understand the purpose and benefits. The motivation people develop after knowing the benefits of particular actions then drives them to commit themselves to an action. Rescher $(1988,5)$ argues that "their desire will motivate them to engage in the action. When they see how they benefit from a particular action, people tend to develop commitment and perseverance." (see also Schneider and Ingram 1990)

Also, according to Darwall (1983), when people know why they have to engage in certain activities, their practices become consistent and not in conflict with each other and, more importantly, contribute to goals set. Understanding reasons becomes a guide to rational actions or actions that are in line with goals. The commitment to accomplish goals encourages them to think about how their actions are systematically connected with each other and also to the goals. This way of thinking is supported by Habermas' (1984) argument that such reasons result in goal-directedness in actions.

The method discussed above illustrates how qualitative research can be adapted and its role reshaped to contribute to change in assessment practices. It highlights the challenges that are likely to be experienced when research is used to facilitate education in a non-didactic manner, by describing and discussing how the adaptation and reshaping of a method in this specific case, made teachers aware of the need to think about the goals of their lessons when choosing and deciding on assessment 
strategies.

\section{Analysis}

By using two sources, the study produced data which we could compare and from which we identified common threads and variances. Data obtained through observations was reflected upon to establish how it confirmed or challenged data obtained through interviews ((Phillips 2000, Roth 2002a and b).). This resulted in thematically sorted and cross-referenced data. Working inductively through it (data) allowed the framework for the findings presented here to emerge. Strengthening the data were the teachers' views about CA. They reflected their understanding of its implications for the decisions they took about their teaching strategies and their motivation or commitment to using it. This was a commitment that would result from the confidence to use the programme because of believing that the individual had the capacity to do so effectively.

Even though Phillips (2006) seems unconvinced by this kind of design, we believe that the systematic inquiry aligned with the deliberate intervention helped us provide insights not on the basis of theoretical abstractions only but the teachers' accounts as evidence as well.

The analysis revealed two main points; namely, that

(i) the choice of assessment items and tasks was environment/context-bound that encouraged the implementation of CA

(ii) lack of professional judgment of assessment tasks as a product of common sense 


\section{Choice of Assessment tasks and items and the environment/context of teaching}

The reasons for the choices made by the teachers became clear when they responded

to the question: "why did you use the exercise for this class work?

NB: I just do as expected - the exercise is given. Even when I give a long test, I mainly use a number of what is in the book. That's, I think, how we are helped to deal with this new policy.

NA: I take them from the book, they cannot be wrong. Anyway, I do not have to develop assessment items. Why spend time on this when it has been done?

MN: Usually they (assessment items) are provided ...that is how the system works in Social Studies and this helps us [to] cope with this new policy.

DN: The ones in the book are fine that is why I use them.CA is timeconsuming and starting to think I can prepare my own assessment when this is done for me will make my job impossible. The paper work required by this $C A$ makes it impossible to do anything else. I used to give a few tests during the year but now everything you teach has to be assessed. Things are just difficult and it is hard to do everything these days.

This narrow cause-effect determinism made teachers to take it for granted that using the suggested exercises had some benefit and saved them time to think about items that were likely to help learners meet the requirements of the lesson objectives. They could not imagine official documents suggesting anything that would compromise what they had to assess. Rather than look critically at the suggested exercises to establish their appropriateness for testing the set objectives, their deference to authority made them take for granted that what is official had to be acceptable.

This is deference that highlights a curriculum tradition that is framed in terms of what teachers assumed to be public needs (cf. Gramsci, 1971) that the school being needed to address needs by implementing structured and codified attitudes. Priority for them was what would be appropriate to their context with its valued cultural peculiarities and institutions. They seemed to be an assumption that what is suggested is valuable 
and there was thus a rational for using it to assess. As agents of a state mandated policy they were expected to carry out the mandate faithfully once well developed for them.

The common-sense that seemed to drive the teachers was primarily concerned by a need to implement, as is practice, what had been pre-determined items and, in their view, officially considered as appropriate to the teaching-learning experience that is desired. As a stance, it placed great importance on the teacher as a practitioner driven by rationality that required to consideration to establish whether or not it would lead to the acquisition of what the lesson objectives pointed to. Therefore, we use the term common sense to describe this consciousness as an uncritical way in which the teachers viewed the assessment exercises. Gramsci (1971) describes it as “... the uncritical and largely unconscious way in which a person perceives the world" (p. 63). These perceptions may not be the correct way of thinking but they are solid and inform norms of conduct, therefore they cannot be reconstructed without being challenged. This view resonated well with the observation data. Here is an example:

A lesson on the position of Mozambique (page $112 \mathrm{~S}$. S Books) had the following objectives:

At the end of the lesson you should be able to:

- locate Mozambique in [sic] a map

- list the countries that share borders with Mozambique

- name the ocean that borders on [sic] the coast of Mozambique.

The suggested exercise was as follows:

1. Which countries in Southern Africa are bigger than Mozambique?

2. Which countries in Southern and Central Africa are smaller than Mozambique?

3. Choose the missing word from the list and complete each sentence. [This time learners had to raise their hands to provide responses]

a) Mozambique is found in the part of Africa. 
4. A greater part of Mozambique is

the tropics.

(outside; within)

5. List six countries that share borders with Mozambique.

To support learners in carrying out this task, teacher MN asked learners to open page 112 of their Social Studies books and respond to questions in the exercise. Whilst learners were busy, a summary of the lesson content taken from the book was written on the board:

Mozambique is one of the republics in Southern Africa. She shares borders with Swaziland, South Africa, Zimbabwe, Zambia, Malawi and Tanzania. Mozambique is washed by the warm Indian Ocean. She can use the sea to transport goods cheaply to other countries.

Thereafter, learners were left to themselves to work out the correct answers. They referred to their books or to each other for help. MN moved around to check the answers they were writing in their books. This was done quietly. She indicated correct or incorrect answers through ticks and crosses. Instead of using the map provided on page 112 of their textbooks to answer questions, many learners simply went through the summary that was on the board to identify answers. This went on until all learners had responded to all questions and received ticks for them.

According to Bernstein (2001), any textual production in a given context depends on the acquisition of a specific coding orientation to it. For learners to meet the requirements of the set objectives, the assessment items in the tasks should have enabled them to recognize what needed to be demonstrated, select relevant subject content and produce responses that addressed the concepts and principles for which they needed to demonstrate understanding. But the evidence provided here indicates that rather than reflect on the suggested exercise and establish its appropriateness to the lesson objectives, the teacher took it for granted that its items addressed the 
knowledge and skills implied by the objectives and for which learners needed to be tested.

Her assessment practices highlighted concerns that have been raised about curriculum work that is driven by a managerial framework based on an assumption that as long as orderly steps are followed in delivering officially considered appropriate content and procedures to the teaching-learning experience that is desired then service is being delivered. The lack of awareness of the misalignment between what the exercise required and nature of set objectives is worrying. Tyler's (1982) argument is that lesson objectives point out the learning that has to occur. Such learning cannot be achieved through passive exposure to ideas but through active participation in learning experiences that make knowledge acquisition intelligible. The teacher whose assessment practice is examined here did not reflect on the quality of learning that would be tested by the exercises she chose to use. This performance rather than competence focussed stance was also evident in the other lessons we observed.

DN taught a lesson on the Climate and Drainage System of South Africa (page $123 \mathrm{~S}$. S books). It had the following suggestions with regard to objectives:

At the end of the lesson you should be able to

- understand the reasons for the climatic conditions of South Africa during winter and summer

- explain the influence of the three main rivers of South Africa to these conditions.

A fill in the gap exercise, with possible answers provided was suggested. There was a need to re-think these questions and this was not done. The teacher dealt with the exercise in the following way: 
Teacher: The temperatures of South Africa range from 0 to 20 degrees $C$. (winter, spring, summer) [Silence, learners could not respond to this question and teacher continues], go back to page 123 first paragraph and lookfor the answers.

Learners: [They looked at their textbooks. The teacher moved around to check if they were all looking at the right page in the text. When a group identified the answer, they raised their hands to provide the answers]

Teacher: Let us all say it!

Learners: Winter [in chorus]

Teacher: Yes! In summer the temperatures range from to (30degrees $C, 15$ degrees $C$, 0 degrees $C$ )

Learners: [all three] 15 degrees $C$ to 30 degrees $C$

Teacher: Good! In South Africa there is more rain along the Coast

than in the A type of climate is found around

Cape Town. (East, West, North, Mediterranean, Sub-tropical)

Learners: [the pair pointed at by teacher] there is more rain along the West than North coast. A Mediterranean type of climate is found around Cape Town

Teacher: Are they correct?

Class: No! [they shouted]

Teacher: Who can help them? What is the correct answer here?

This was the process until all questions were answered correctly. The approach of the rest of the teachers was the same, no attempt was made to think carefully about the exercises and how they could be used to facilitate learning. Even though teachers were made aware that the curriculum documents provided were to be used as a guide, they were unable to reflect and display critical understanding of the lesson objectives and how they could be translated effectively into assessment items in the context they had to teach

A critical stance towards the provided exercises would have resulted in the teachers using professional discretion and rephrasing the items in a manner that could reveal whether or not learners had the cognitive competences required by the objectives. As Rault-Smith (2001, 5) explains; "transformation of assessment thinking requires educators to begin thinking about assessment, discussing assessment, debating assessment, bringing discussions about assessment to the staff room." However, there 
could be no reflection on what was taken for granted without us creating an environment in which we could encourage the teachers to reflect on the exercises in relation to the purpose of the lessons. This was necessary to initiate the development of a different professional disposition on their part. The decision-making authority afforded to them by CA was not taken advantage of in the face of official documents and their confidence to do this has to be built.

Investment in, or reliance on, official documents, evident in the data presented here, had to be discouraged for the teachers to actively use CA for its purpose. As it is evident in the evidence presented here, the research process served as resource for them to realise that they had the authority to judge and stray from what was suggested in official documents and create their own assessment tasks. The nature of this professional judgement is looked at in the following section.

\section{Lack of professional judgement and Common-sense}

Teachers had to enable us understand the reasons for their choices and the manner in which they mediated tasks for the learners. The following conversations with three teachers, taken as examples of the process, illustrate how this happened.

\section{Teacher NA}

Researcher: The objective of the lesson was to enable learners to work out the latitudinal position of Zambia? [Here reference is made to the relevant section in the text-book used by the teacher], now that they have done the exercise, do you think the learners have an idea of what they need to do to locate a place or country on a map if they have no flash cards?

NA: Well, you saw for yourself, they generally did well in the exercise I gave them. What do you mean?

R: your objective was to help learners locate Zambia; do you think being able to indicate practically on the board is for example, an indication of being able to tell where Zambia is in relation to the other countries?

NA: I can see your point, but they knew the answers how else was I to expect them to show me where Zambia was? 
R: Yah! Can you explain to me what you would have done if you had no flash cards .... perhaps only an atlas?

NA: You mean look for Zambia in an atlas?

The dialogue highlights that the teacher did not have an idea of how best the lesson could have been taught so as to enable the learners to understand place depiction. The way she responded to the questions confirmed her lack of understanding of what she needed to do as a geography teacher, without a cue to an alternative to her assessment strategy. More probes and prompts from the researcher made her realize the possibility. The dialogue continues:

NA: Yes, that is what they say to us at workshops. ... perhaps they could learn to do this in another way that I did not think of when I planned the lesson ... [quiet for sometime] I could have used the atlas.

R: how - what do you think?

NA: Using the index to plot the location of Zambia on a map [pause] Yah! It is possible to use the easy way and end up awarding marks to students who can just repeat answers when they are not deserved ...

R: What do you mean with awarding marks where they are not deserved?

NA: Awarding marks to people when they do not understand why they are correct...

The process enabled the teacher to think more deeply about how she taught. From her responses it is clear that, initially, she was simply giving the rhetoric learnt in her preservice courses as a response. She was familiar and could repeat the language used in the CA programme. Through probing she was compelled to reflect on the answers she gave. She then explained that teaching and assessment strategies have to demonstrate the way she understood the purpose, nature and scope of the objective of her lesson and she needed to have created a situation in which the lesson objective was dealt with through using the index in an atlas:

$\mathbf{R}$ : Okay going back a little bit to the objectives [reference is made to the objectives as stated in the textbook], how can we use them in the classroom? 
NA: I suppose to guide both the teacher and the learners on what they should be able to achieve at the end. That's what they tell us...

$\mathbf{R}$ : Then how else can we use it to ensure that the learners become aware of what is important to do when locating places on a map? You as a teacher knew the lesson objective, but did the learners understand what they were required to be able to do?

NA: Okay, I see now, this is what we struggled with during my training. We were taught that before you start teaching, learners should know the objectives of the lesson. Tell them exactly what is expected of them by the end of the lesson.

R: How were you taught to do this?

NA: We had to analyse the objective.

$\mathbf{R}$ : What did this analysis involve?

NA: Finding out what learning something has to bring about in terms of first thinking and then acting? But, that's hard - it requires thinking about it..

$\mathbf{R}$ : Let's try to think together

NA: I know I had to make them refer to the index - are you coming in tomorrow, let's talk during break...

R: Good, I am looking forward to your thoughts tomorrow

The uneasiness caused by the conversation revealed to the teacher that she took for granted that learners knew what needed to be done when locating places on a map. Instead of using a form of assessment that was slower in pacing and focusing on learners' progress in fulfilling the lesson objective, she resorted to a strongly classified and framed strategy (Bernstein 1971). Learners' recognition of subject content rather than its understanding was prioritized. It was faster to teach location by means of flash cards that could be removed and replaced on a map on the board. Without subjecting the teacher to a research process aimed at making her aware of the implications of such a teaching strategy, there would be no hope of her developing an appreciation (good sense) of what learning ideals were significant to the CA programme. As a conversation with teacher NB also indicates, this proved to be a useful strategy. 


\section{Teacher NB}

From the conversation with the teacher it became clear that it was customary that learners were given work to do only at the end of a lesson. The teacher had not thought about how helpful it would be to use assessment during the course of the lesson to diagnose misconceptions as they occurred and reinforced good learning practices. When asked why he only used assessment at the end of his lesson: "you have used oral questioning and then gave learners homework only at the end of the lesson - can you tell me why it was important to assess learners in this way?" the teacher responded:

NB: I find it more suitable to those who follow the lesson if I mix questioning with teaching. Also oral work helps the learners to revise and clarify for themselves what they had been listening to. Written work as follow up reinforces learning especially for those who are good at writing.

R: Now, what is your view, in this particular lesson, did it work?

NB: Yes I think so. As, I hope, you observed, questions they could respond to were the ones they got right when writing. The question-and-answer strategy I used helped them not to forget the subject content and they easily picked it up from their books.

R: Why did this occur?

NB: What is important for me when I teach and assess is to make sure that 'things' taught stick in their minds and for that to happen they need to work on it again and again. The reason that I also used written work is because they should also be able to write it down for me after the repetition they have gone through in the lesson, and besides examinations are in the form of writing so they should get used to that.

R: But this assessment does not cater for all the learners ... how do you reconcile the two?

NB: Yah but like I said the exam requires this

NB's responses demonstrated his lack of understanding of the cognitive development principle crucial to the CA programme. What affected the implementation of this principle was interesting to clarify, because his assessment strategy and justification for it depended on how he interpreted this principle. This became clearer as the conversation with him continued: 
R: So you use repetition for this purpose?

NB: Yes because unless they can associate a question with a specific answer, they feel lost and it will be difficult to put them back on track.

R: What you mean with being lost?

NB: I mean that if I do not make them to do the same questions using different methods they will not master the correct responses

R: Don't you think that it is possible for learners to give you these correct answers whilst not having mastered them?

NB: But that is not possible once they answer the questions correctly then it means they know.

R: now that they all responded correctly to your questions are you confident that your learners can locate Ghana if provided with a blank map of Africa what would they need to do this if you are not there to give them flash cards with names on?

NB: I am not sure, may be yes and, may be not but what do you mean - what do they need?

R: Why do you feel this way?

NB: because they responded to questions correctly - how else could I have helped them to be able to do it on their own?

R: Let's try and work this out together.

NB: Well, of course in the absence of flash cards they will have to use the index in their atlases.

R: Correct. Why did you not let them use this in the lesson?

NB: I have taught them how to use an atlas index before - they know how to use the information to locate places .....[he pauses] ... oh yes, are you saying I should have found out if the learners knew what they needed to do to answer the questions in the exercise, if so, why did the question not ask them to do so ... are you saying to me the Curriculum Centre people wanted me to think of this myself. It's beginning to be clear .... Is this what they mean in the CA programme when they talk of recycling the learning process until learners master the content taught .... uh .. this is really interesting - I never thought of it this way - now I see what is meant when they say doing CA can take a long time - it would have taken longer to see if the learners were able to answer the questions

The teacher was allowed to think aloud uninterrupted. Like teacher NA, NB was pushed to think about how he taught and determine the educational value thereof to the lesson objective he had to help learners fulfill. Initially, his responses were orientated towards what he was given in the support materials and it was through persistent probing that his assessment strategies were thought seriously about. Rather than criticising the teacher directly, I pointed towards a way in which learners' cognitive development would have been enhanced. The research method also became invaluable in the conversation I had with teacher $\mathrm{MN}$ on her remedial strategies. 
At first MN talked and explained what she believed to be remediation in a manner that exposed her misconceptions of how CA was to be used to remedy learning problems. For MN, remediation equaled simplified reiteration or repetition of work done. When I first began to talk to her she had not realized that engaging learners in repetitive work as a corrective measure could not produce correct answers based on understanding the concepts that were to be taught.

\section{Teacher $M N$}

MN: Sometimes after assessing especially when most learners have not performed well I have to go back and re-teach the lesson.

R: How helpful is that?

MN: When I have to repeat a lesson I usually tell the ones with no problems to read on their own when non-masters do the corrections. Also, Social Studies has a lot of drawings especially when we learn about a particular country and I usually instruct them to draw and label some important things that I will have specified to them. Sometimes I give them more questions that are a bit challenging cognitively compared to the ones they answered at first.

R: This is interesting [we re-wind the video] how did you do what you are just telling me, let us see?

MN: Actually in those lessons I did not divide learners according to their performance, they all worked together to help the non-masters. They can always do other work at their spare time

R: Then what happens when the 'non-masters' do different work, are all the learners going to do some of the work as reinforcement.

MN: No usually I do not make the weak ones do it.

R: Can you tell me more about how make these weaker ones do their corrections?

MN: I give them notes that they are going to read and also ask them to refer to their books before they start answering the questions. Then I write questions on the board and we discuss them. Because there isn't enough time to work with individuals, when corrections are done as a class it is much better.

R: Oh, but these are learners who have not performed well, how do you help them understand why their answers were wrong?

MN: Once I have shown them where to find correct answers to the various questions then they are usually fine. 
For MN, remedial work had to do with helping learners know were to find correct answers. As the conversation continued, what she meant became clearer:

MN: Their problem was that they could not respond to questions I gave them, then I gave them the same questions to work on and that is what CA requires.

R: How was doing this dealing with their inability to give you correct answers in the first instance?

MN: But there isn't enough time for me to look at each learner's problem so I concentrate on general issues. We were told to give learners the same test until they master it and that is what I am doing.

R: Don't you think their failure to respond to questions could be an indication of other challenges they have?

MN: Maybe [demonstrates a bit of irritation]

R: Now tell me, how did you take such a possibility into account when doing remedial work?

MN: I see what you are pointing at but if that is the case what should I have done?

R: What do you think you should have done?

MN: Maybe first find out why a wrong answer was given and then work on the remedial activities in another way but I am not sure how.

The conversation made the teacher realise that effective remedial work cannot be generalised, rather it has to address the reasons wrong answers were given. However, she still could not explain how she would try and deal with such reasons when planning remedial work. This was her challenge. In addition, much as she acknowledged that addressing learners' individual needs was important when conducting remedial work, she felt there was inadequate time to deal with such needs. Instead, it was a priority that learners knew what to do to select correct answers from the content that was taught when they had to read texts on their own.

By focussing on the inter-actional strategies employed by the teachers, and trying to determine how they served lesson objectives, it was possible to advance knowledge about the conditions under which teachers as a target population would contribute to aims of the CA programme. Even though we could not continue working with them over the three months to ensure the creation of these conditions in their schools, we 
hope the awareness we raised will encourage them to take the initiative of continuing the reflective process they had started, and that they will realise ways in which they can facilitate the cognitive development of their learners. We are in no doubt that the research method used with them has begun this professional judgement.

According to Hirst (1982) also:

...understanding the nature of curriculum objectives is first and foremost a matter of understanding what is involved in the acquisition of knowledge... It would seem likely than that our analysis of the nature of educational objectives will in general reveal [that] .... What we need ... is a much more profound grasp of ... their logical interrelations. If we can get the ends clearer maybe we can plan more effective means (p.295 -6).

The view confirms, amongst other arguments, Pinar et al.'s (1995) assertion that the effective implementation of any curriculum programme requires curriculum expertise or literacy that provides the possibility of generating interpretations and views of a situation on which to base a plan of action. Such planning should ask questions of feasibility, instead of prioritising the mastery of routine procedures. Therefore, the research process we employed was not ideologically 'innocent', in that "many methods attempt to determine an objective finding by having the researcher taking a disinterested position, dialogical approaches assume that it is impossible to remove bias completely" (Gitlin, 1990, 448). Rather, it was deliberately aimed at alerting teachers to the need for further professional development, by triggering a 'bottom up' development in a non-didactic manner. Teachers were gently guided into a way of thinking about their assessment practices. Now that they realized what should have been happening with CA, through the cues and probes to which they were subjected, the hope was that they will, in turn, cause discomfort for colleagues, and alert them to the fact that traditional procedures of designing assessment items are inappropriate for promoting the aims of the CA programme. We hope they will have confidence to do 
so and cascade the development process they have begun to undergo. The dilemma faced when having to end the dialogue with the teachers, without establishing whether they had been able to translate principles into effective teaching strategies, is lingering and needs to be part of a another project that would specifically be engaged with this developmental aspect.

\section{Concluding Remark}

Studying teachers' choices and use of assessment tasks revealed how their environment/context seemed to influence the manner in which they dealt with officially provided professional support. As an immediate context, it determined their common-sense. The appropriateness of this common-sense to their attitude towards the provided support would not have been understood without coupling an analysis of their choices with their explanations. Using dual methods of inquiry, we hope, enabled us to understand that unless a relevant consciousness that could alter the commonsense of the teachers into good sense, it will be difficult for them to develop a critical stance they need when dealing with officially provided professional guidance. For Swaziland to implement CA effectively, teachers needed to be re-socialised. The benefits gained from initiating this through the study are bound to filer through to their colleagues and other structures in their work settings.

\section{Selected References}

Ball, S. J. 1994. Education Reform: A Critical and Post-structural Approach. Buckingham: Open University Press.

Bernstein, B. 1971. On the Classification and framing of educational knowledge. In Knowledge and Control, ed. Michael F D Young, 245-270. London: Collier Macmillan. 
Bernstein, Basil. 2001. From Pedagogies to knowledges. In Towards Sociology of Pedagogy. The contribution of Basil Bernstein to research, ed. Ana Morais, Isabel Neves, Hary Daniels and Brian Davies, 365 - 381. New York: Peter Lang.

Bilmes, J. 1986. Discourse and Behaviour. London: Plenum Press.

Cardorna, C. M. 2000. Regular Classroom Teachers' Perceptions of Inclusion: Implications for Teacher Preparation Programmes in Spain. In Educational Research in Europe (Yearbook), ed. Christopher Day and Dolf Van Veen, 37 48. Aperldoorn: Garant Publishers.

Cochran-Smith, M \& Lytle, S. 1999. Relationships of Knowledge and Practice: Teacher Learning in Communities. In Review of Research in Education, ed. Asghar Iran-Nejad and David Pearson, 249-303. Washington: American Educational Research Association.

Day, C. 1999. Developing Teachers: The Challenges of Lifelong Learning. Philadephia: Palmer Press.

Davies, B., D. Sumara and R. Luce-Kapler. 2000. Engaging minds: Learning and Teaching in a Complex world. London: Lawrence Erlbaum Associates.

Darwall, S. L. 1983. Impartial Reason. Ithaca: Cornell U.P.

Fairclough, N. 1992. Discourse and Social change. Cambridge: Polity Press.

Flick, U. 1998. An Introduction to Qualitative Research. London: Sage Publications.

Gall, J. P, M.P. Gall and W. R. Borg. 1999. Applying Educational Research: A Practical Guide. USA: Longman.

Gitlin, A and Russell, R. 1988. Alternative Methodologies and the Research Context. In Power and Method: Political Activism and Educational Research, ed. Andrew Gitlin, 237 - 253. London: Routledge.

Gitlin, A. 1990. Power and Method: Political Activism and Educational Research. London: Routledge.

Gramsci, A. 1971. Selections from the Prison Notebooks. London: Lawrence and Wishart.

Gule, E. D. and Khumalo, C. P. 1997. Social Studies Grade 6: Teacher's Guide. Swaziland: Macmillan Publishing Company.

Habermas, J. 1984. The Theory of Communicative Action. V. 1. Boston: Beacon. 
Hirst, P. 1982. The Nature and Structure of Curriculum Objectives. In Planning in the Curriculum, ed. Victor Lee and David Zeldin, 290 - 312. Hodder and Stoughton with OU.

Lather, P. 1986. Research as Praxis, Harvard Educational Review 56: 257-277.

LeCompte, M. D. and Preissle, J. 1993. Ethnography and Qualitative Design in Educational Research. London: Academic Press.

Martinez, A. M. and Pares, N. S. 2000. Teachers' discourses in Social Learning. In Educational Research in Europe (Yearbook), ed. Christopher Day and Dolf Van Veen, 155- 172. Aperldoorn: Garant Publishers.

Merriam, S. B. 1998. Qualitative Research and Case study Applications in Education: Revised and Expanded from Case study Research in Education San Francisco: Jossey-Bass Publishers.

Merriam, S. B. 2002. Qualitative Research in Practice: Examples for Discussion and Analysis. San Francisco, CA: Jassey-Bass.

Ministry of Education. 1994. Module: Swaziland Continuous Assessment and Remediation Handbook. Manzini: Macmillan.

Moser, C. A and Kalton, G. 1986. Survey Methods in Social Investigation. England: Gower Publishing Company.

National Education Review Commission Report, 1985. Mbabane: Government Printer.

Nsibande, R and Modiba, M. 2005. Developing teachers through research: reflections on method, South African Journal of Education 25: 203-209.

Phillips, D. C. 2000. Post-positivism and Educational Research, 1938 -Lanham Md.:

Rowman and Littlefield.

Phillips, D. C. 2006. Muddying the Waters: The Many Purposes of Educational Inquiry. In The Handbook of Research in Education: Engaging Ideas and Enriching Enquiry, ed. Clifton F Conrad and Ronald C, 331 - 348 Serlin. Sage: Thousand Oaks.

Pinar, W. F., W. M. Reynolds, P. Slattery and P. Taubman. 1995. Understanding Curriculum. New York: Peter Lang.

Rault-Smith, J. 2001. Developing quality assessment practices, The Journal of the Gauteng Department of Education 6: 4 -10. 
Rescher, N. 1988. Rationality: A Philosophical Inquiry into the Nature and Rationale of Reason. Oxford: Claredon Press.

Roth, W. 2002a. Being and Becoming in the classroom. Westport, Conn.: Ablex Publication.

Roth, W. 2002b. At the elbow of another: learning to teach by co-teaching. New York: P. Lang

Schneider, A and Ingram, H. 1990. Behavioural Assumptions of policy tools' Journal of Politics 52: 510 - 529.

Stenhouse, L. 1975. An Introduction to Curriculum Research and Development. London: Heinman.

Tomaney, J. 1994. Beyond Taylorism and Fordism. In Post-fordism: A reader, ed. Ash Amin, 57-194. Oxford UK: Macmillan Publishers. 